\title{
A CONFIRMATORY FACTOR ANALYSIS OF THE NEW MALAYSIAN INDEX OF ELDERLY WELL-BEING: A PRELIMINARY FINDINGS
}

\author{
RAHIMAH IBRAHIM ${ }^{1,2^{*}}$, HAZWAN MAT DIN², SITI FARRA ZILLAH ABDULLAH ${ }^{2}$ \\ AND TENGKU AIZAN HAMID ${ }^{2}$
}

${ }^{I}$ Malaysian Research Institute on Ageing, Universiti Putra Malaysia, 43400 Serdang, Selangor, Malaysia

${ }^{2}$ Faculty of Human Ecology, Universiti Putra Malaysia, 43400 Serdang, Selangor, Malaysia

*Corresponding author: imahibrahim@upm.edu.my

\begin{abstract}
Malaysia is experiencing rapid ageing. With such rapid demographic changes, the need for understanding elderly well-being become a necessity. This study aims to validate a new developed Malaysian index of elderly well-being (MIEW) among the Malaysian community-dwelling elderly. A cross-sectional study was conducted among the elderly in Negeri Sembilan, Malaysia. The preliminary MIEW contained 40 items and is composed of five factors; economic, health, social, psycho-spiritual and environmental well-being. Confirmatory factor analysis using maximum likelihood estimation method was conducted to assess the validity and reliability of the instrument. A total of 629 respondents participated in this study, with an average age of 70.36 years old. Confirmatory factor analysis yielded 18 items with five factors. The model fitted the data well, showing strong construct validity and reliability of the instrument. The findings from this study suggested an acceptable level of validity and reliability for the new instrument. However, MIEW should be used with caution as the discriminant validity of social and environmental well-being was unsatisfactory. Further research in this section is recommended.
\end{abstract}

Keywords: Scale validation, ageing, measurement, quality of life, life satisfaction, older adults, older persons

\section{Introduction}

The impact of population ageing may not be noticeable enough to be recognized in the development of policies and programmes since many countries in Southeast Asia are still considered to have relatively youthful populations. However, in reality, the accelerated pace of population ageing particular to this region may pose a problem in the next two to three decades, as the number of older people in the total population is projected to increase from $9.6 \%$ in 2016 to $21.18 \%$ in 2050 (United Nations Economic and
Social Commission for Asia and the Pacific Social Development Division, 2017). With such rapid demographic changes and simultaneous economic and social changes in progress, there is a pressing need to enhance our understanding of how these transformations will impact the well-being of older people. Based on demographic projections, Malaysia ranks the fourth fastest ageing nation, following Singapore, Columbia and India (Sim \& Hamid, 2010). Thus, the main challenge for developing countries like Malaysia is to maintain the well-being of older people in the midst of rapid population ageing and other socio- 
economic changes that would drive the country to grow old before becoming rich.

Due to the possible devaluation and marginalisation of older people in development, concerns for their wellbeing have been championed and reiterated in many international assemblies (e.g. World Summit for Social Development, Millennium Development Goals, Two World Assemblies on Ageing). Malaysia has included this significant matter in national policies and development-planning documents, including The 10th Malaysia Plan, National Welfare Policy, National Policy for Elderly, National Policy for Older Persons and National Health Policy for Older Persons. Pursuant to the Madrid International Plan of Action on Ageing 2002 and pertinent regional strategies, the revised National Policy for the Elderly 2011 adopted a more comprehensive approach to elderly well-being, incorporating economic, health, social, psycho-spiritual and environmental domains.

Theories and indices of well-being usually differentiate between objective, or external factors related to a person's life circumstances, and subjective, or personal assessment of objective conditions that harbour values of the self and the society within which an individual lives. The concept of well-being has been expanded to standard of living, health and vitality, capability or positive functioning, and the degree of fit between perception and reality, and engagement in valued life activities (Kahn \& Juster, 2002; Sen, 2001; Ryan \& Deci, 2001; Naess, 1999; Diener \& Suh, 1997; Converse \& Rodgers, 1976), which illuminate the Easterlin's paradox of economic development or increase in gross domestic product and happiness (Choudhary et al., 2011). As such, the increased interest in taking stock of gross national happiness was highly based on subjective well-being, defined and measured as satisfaction with life in general (unidimensional) and satisfaction with various aspects, or domains, of life (multidimensional). The concept of well-being was found to be used interchangeably with quality of life (Ju et al., 2013) that focuses on primarily objective indicators, but life satisfaction and happiness were concepts that relate solely to subjective well-being (Luchesi et al., 2018). Some authors went further to discriminate between happiness and life satisfaction by stating that life satisfaction has a more lasting impression, which is cognitively based, compared with happiness, which is based on emotional state (Meléndez et al., 2009; Helliwell \& Putnam, 2004).

One of the approaches to measuring multidimensional well-being is through self-reported happiness and life satisfaction. However, existing instruments in this field take different conceptualisation of wellbeing as their starting point. The commonly used PANAS scale (Watson et al., 1988) describes affective-emotional aspects of well-being. In contrast, Satisfaction With Life Scale (SWLS) (Diener et al., 1985) aims to measure cognitive-evaluative facets of well-being. The Psychological Well-Being (SPWB) (Ryff \& Reyes, 1995) focuses on eudaimonic well-being and assesses psychological functioning. The five-item Short Depression-Happiness Scale (SDHS) (Joseph et al., 2004) developed for use in therapeutic settings assesses well-being as a continuum between the two states of depression and happiness. The recently developed Marwick-Edinburgh Mental Well-Being Scale (WEMWBS) (Tennant et al., 2007) was designed to capture a wide conception of well-being, including affective-emotional aspects, cognitiveevaluative dimensions and psychological functioning. All these instruments cover aspects of mental illness as well as mental health.

There is a growing demand for the monitoring of well-being and the promotion of healthy ageing among elderly population. 
In addition, valid and reliable instrument is needed, considering the advancing evidence-based research. Findings from literatures review showed there is a need for a validated and reliable tool specifically tailored to measure well-being among the elderly population. Therefore, the current study aims to validate the newly developed Malaysian index of elderly wellbeing (MIEW) among the elderly living in community in Malaysia.

\section{Methods}

\section{Study design and respondents}

Data of the current study were derived from a cross-sectional study, "Development of Malaysian Elderly Well-Being Index", in 2015. The study was conducted among older people aged 60 years and above in Negeri Sembilan based on the sampling frame obtained from the Department of Statistics, Malaysia. Negeri Sembilan was selected as the location of the study in order to have an equal distribution of urban and rural areas. The sample size was determined using a $6 \%$ margin error, involving 78 enumeration blocks (EBs). Every EBs is fixed to only 13 households and each one involved only single respondents. Households were selected at a sequence interval of 15 and the first sample started at Point A of each EB provided. Selected respondents were invited for interview sessions at the nearby community centre. Prior to the interviews, respondents were briefed on the study and were required to sign a letter of consent. A total of 629 respondents were successfully interviewed based on a structured questionnaire by trained enumerators.

\section{Development of Malaysian Index on Elderly Well-being}

The Malaysian Index of Elderly Wellbeing (MIEW) is a multidimensional index researcher-developed based on the five domains of well-being in the new Malaysia National Policy for Older
Persons; economic (productive ageing), health (healthy ageing), social (active ageing), psycho-spiritual (positive ageing) and environmental (supportive ageing) well-being. The 40-item instrument is an integration of multiple domains regarding the circumstances and experiences of ageing to become an index to measure the well-being of older Malaysians. Items for each domain were initially identified from focus group discussions, published questionnaires, and well-being theories. The item was rated on a five-point Likert scale; Never (1) to Always (5) for items 1, 2, 3, 4, 5, $6,7,8,11,12,13,14,15,16,17,18,19$ and 20; Not Enough (1) to More Than Enough (5) for items 9 and 10; Strongly Disagree (1) to Strongly Agree (5) for items 21, 22, 23, 24, 25, 26, 27, 28, 29 and 30; and, Not Sure At All (1) to Very Sure (5) for items $31,32,33,34,35,36,37,38,39$ and 40. The content validity of MIEW was assessed by a panel of experts; two gerontologist, a psychologist, a geriatrician and two researchers. The panel members reviewed the proposed items to rate the cultural relevance and appropriateness of the items in terms of the construct being measured. The English generated items were then translated into the Malay language using the forward-back translation approach with expert, bilingual translators. Using the forward-back translation method, the proposed items were first translated into the Malay language and then back-translated into the English language for an evaluation of the translation in the native language. The items of MIEW were presented in pair for both the Malay and English items. The English items of MIEW within their factors are presented in Table 1 . The face validity was assessed during a pilot study among 63 samples of the elderly. Respondents were asked to provide feedback on anything on the items in term of their comprehension of the items. The results showed that the items were adequately understandable and culturally relevant to the respondents. 
Table 1: Malaysian index of elderly well-being item description

\begin{tabular}{|c|c|}
\hline Item & Description \\
\hline & Social \\
\hline Q7 & $\begin{array}{l}\text { I have close relationship with family } \\
\text { members }\end{array}$ \\
\hline Q8 & $\begin{array}{l}\text { I have someone to help me when } \\
\text { needed }\end{array}$ \\
\hline Q19 & $\begin{array}{l}\text { I am in contact with my immediate } \\
\text { family (parents, children, siblings) }\end{array}$ \\
\hline Q20 & I am in contact with friends \\
\hline Q29 & I have someone whom I love \\
\hline Q30 & $\begin{array}{l}\text { My opinion/ advice is always } \\
\text { considered by my family. }\end{array}$ \\
\hline Q39 & I have someone as a confidante \\
\hline \multirow[t]{2}{*}{ Q40 } & $\begin{array}{l}\text { I am not being controlled by my } \\
\text { family }\end{array}$ \\
\hline & Economic \\
\hline Q9 & I have savings and assets for old age \\
\hline Q10 & I have money for daily expenses \\
\hline Q13 & I worry about my financial situation \\
\hline Q14 & I spend on activities I enjoy \\
\hline Q23 & $\begin{array}{l}\text { I can afford to pay for household } \\
\text { repairs }\end{array}$ \\
\hline Q24 & I always have money for emergencies \\
\hline Q33 & I am free from debt \\
\hline \multirow[t]{2}{*}{ Q34 } & I buy what I want \\
\hline & Health \\
\hline Q1 & I can sleep soundly at night \\
\hline Q2 & I have good appetite \\
\hline Q11 & I can manage my stress \\
\hline Q12 & I maintain a healthy weight \\
\hline Q21 & I am always energetic \\
\hline Q22 & $\begin{array}{l}\text { My daily activities are often affected } \\
\text { by pain }\end{array}$ \\
\hline Q31 & My health is under control \\
\hline \multirow[t]{2}{*}{ Q32 } & $\begin{array}{l}\text { I perform daily activities } \\
\text { independently }\end{array}$ \\
\hline & Environmental \\
\hline Q5 & $\begin{array}{l}\text { I can move easily in my } \\
\text { neighbourhood }\end{array}$ \\
\hline
\end{tabular}

Q6 Public facilities in my neighbourhood are functioning

Q17 I can easily access public facilities when needed

Q18 I participate in my neighbourhood community activities

\begin{tabular}{ll}
\hline Q27 & I feel secure in my house \\
\hline Q28 & I can move easily in my house \\
\hline Q37 & $\begin{array}{l}\text { I walk safely alone in my } \\
\text { neighbourhood }\end{array}$ \\
\hline Q38 & I live in a close-knit neighbourhood \\
\hline & Spiritual \\
\hline Q3 & I am at peace with myself \\
\hline Q4 & Life is beautiful \\
\hline Q15 & I maintain my relationship with God/ \\
& Higher Power \\
\hline Q16 & I worry about my future \\
\hline Q25 & I often worry thinking about death \\
\hline Q26 & I have a meaningful life \\
\hline Q35 & My belief influences my behaviour \\
\hline Q36 & My life is enjoyable \\
\hline
\end{tabular}

\section{Statistical Analysis}

Before analysis was conducted, data were screened for missing values, normality, multivariate outliers and item collinearity using IBM SPSS version 20 and SPSS Amos version 19 . Normality was checked through assessment of skewness and kurtosis. Based on the recommendation by Tabachnick and Fidell (2007), an absolute value skewness of $<2$ is used as an indication of data normal. Byrne (2010) recommends an absolute value kurtosis of $<7$ as an indication of data normal. Multivariate outliers were identified through evaluation of the Mahalanobis distance and its respective $\mathrm{p} 1$ and $\mathrm{p} 2$. To assess the multivariate collinearity of the items, tolerance and variance inflation factor (VIF) were used. Tolerance $<0.10$ and VIF $>10$ were considered as an indication for multivariate collinearity of the affected items (Hair et al., 2009). 
Confirmatory factor analysis (CFA) was conducted in AMOS to examine the validity of the MIEW measurement model. The model validity was evaluated through assessment of model fit indices and evidence of construct validity of the model. Based on the recommendation by Brown (2014), the following fit indices were used in this study: chi-square goodness-of-fit [ $[\chi 2]$, Tucker-Lewis fit index [TLI], comparative fit index [CFI], root mean square error of approximation [RMSEA] and standardized root mean square [SRMR]. Additional fit index relative chi-square (Relative $\chi 2$ ) recommended by Bentler (1990) was also used in this study. The following cut-off values were used for indication of model fit: $\chi^{2} \mathrm{P}>.05$, relative $\chi 2 \leq 5$ (Bentler 1990), TLI and CFI $\geq 0.90$ (Bentler 1990), RMSEA and its upper $90 \%$ confidence limit $\leq 0.08$, RMSEA's close fit $\mathrm{P}>.05$, and SRMR $\leq 0.08$ (Brown, 2014). To evaluate the model comparison involving nonnested model, Akaike information criterion (AIC) and expected cross-validation index (ECVI) were used. Model with the lowest AIC and ECVI were considered as better fit (Brown, 2014).

Construct validity was evaluated through convergent and discriminant validity. Factor loading, average variance extracted (AVE) and construct reliability (CR) were used to evaluate the convergent validity. A significant factor loading $\geq 0.5$, $\mathrm{AVE} \geq 0.5$ and $\mathrm{CR} \geq 0.7$ were the indication for convergent validity (Hair et al., 2006). The calculation of AVE and CR were done using the equation suggested by Fornell and Larcker (1981). Discriminant validity was evaluated by comparing the factor's AVE and its squared factor correlations. Discriminant validity was achieved if the factor's AVE exceeds its squared factor correlations (Fornell \& Larcker, 1981). The factor reliability was indicated by $\mathrm{CR} \geq 0.7$ (Hair et al., 2006).

Model revision to improve model fit was done based on the evaluation of strength of item factor loadings and model modification indices (MI). Items with factor loading $<0.5$ were considered for removal from the model. MI was used to screen for the potential of items cross loading without setting for any cut-off values (Hair et al., 2006).

\section{Results}

\section{Preliminary data analysis}

A total of 629 respondents agreed to participate in this study. During the data screening, there were 16 respondents with one missing value, and none of the respondents had two or more missing values. The overall rate of missing values was 0.2 $\%$. These missing values were handled using single imputation method, imputation by mean values. Data file before and after imputation were compared in terms of mean and standard deviation. There was no difference between the datasets, indicating the imputed values did not affect the data markedly.

On inspection of the normality of data, skewness and kurtosis showed the data were considered normal. Skewness absolute value ranged from 0.024 to 1.963 , while kurtosis absolute value ranged from 0.044 to 4.385 . Tabachnick and Fidell (2007) recommend an absolute value of $<2$ for skewness and while Byrne (2010) recommended an absolute value of $<7$ for kurtosis are indicative of normally distributed data. According to Byrne (2010), one can assume multivariate normally if both skewness and kurtosis normality are met. On the assessment of multivariate collinearity to identify redundant items, none of the items had multivariate collinearity based on the assessment of tolerance and VIF.

Upon completion of this preliminary analysis, a total of 629 respondents were included in the CFA. The average age of 
the respondents was 70.36, with a standard deviation of 6.38 . The age ranged from 60 to 90 years old. The data composed of balanced gender of respondents, with $49.1 \%$ of the respondents being men and 50.9\% women. The majority of the respondents were Malay (72.3\%), followed by Chinese $(23.5 \%)$ and others (4.1\%). About $60.7 \%$ of the respondents were currently married, while $39.3 \%$ of them were single. Most of the respondents, $86.8 \%$, had formal education, while $13.2 \%$ of them never had any formal education.

\section{Confirmatory factor analysis}

The MIEW model was specified in AMOS using the maximum likelihood estimation method. MIEW was developed based on five factors of well-being; social, economics, health, environmental and spirituality. Thus, the MIEW CFA model was specified based on the measurement model consisted of five first-order latent factors, 40 items and 10-factor correlations. This model was named as WB-5. WB-5 revealed a poor model fit as showed by all fit indices except for $\chi 2$, RMSEA and SRMR. In order to improve the model fit, WB-5 was revised by examining the items factor loadings.

Initially, 11 items (Q6, Q13, Q14, Q15, Q16, Q17, Q18, Q21, Q22, Q25, Q33 and Q35) with factor loadings $<0.5$ were removed. It was then followed by removal of 11 items (Q1, Q2, Q5, Q6, Q8, Q23, Q32, Q31, Q34, Q37 and Q40) with factor loadings $<0.6$. The researchers decided to set a higher cut-off value of 0.6 for factor loadings. This was due to a large number of items and the aim of this study of reducing the number of items in the instruments. In addition, setting a higher cut-off value can be considered for the development of a new instrument and a factor loading of less than 0.6 should be excluded as they do not contribute to construction measurements (Hoque et al., 2017; Awang, 2012). Further investigation of MI revealed that there was no item cross loading in the model.

In overall, 22 items of the initial 40 items were removed. The revised model was named as WB-5r, which consisted of 18 items. Model fit indices showed WB-5r was an acceptable fit (Table 2). The model met of all fit indices, except for $\chi 2$. However, it was important to note that the value of TLI (0.895) for WB-5r was slightly lower than the cut-off value (0.90) and was considered acceptable in this study. On the assessment of factor correlations, model WB-5r revealed that there was a considerably high factor correlation between social and environmental well-being (0.87). The researchers decided to examine the possible presence of the four-factor model, in which social and environmental well-being were combined.

Table 2: Fit indices of elderly well-being index measurement model

\begin{tabular}{|c|c|c|c|c|c|c|c|c|}
\hline Model & $\chi^{2}(\mathbf{d f}) / \mathbf{P}$ & $\begin{array}{c}\text { Relative } \\
\chi^{2}\end{array}$ & TLI & CFI & $\begin{array}{c}\text { RMSEA } \\
\text { (90\% CI)/ } \\
\text { Clfit P }\end{array}$ & SRMR & AIC & ECVI \\
\hline WB-5 & $\begin{array}{c}2938.12 \\
(730) /<0.001\end{array}$ & 4.03 & 0.764 & 0.779 & $\begin{array}{c}0.069(0.067 \\
0.072) /<0.001\end{array}$ & 0.073 & 3118.59 & 4.97 \\
\hline WB-5r & $\begin{array}{c}574.08 \\
(125) /<0.001\end{array}$ & 4.59 & 0.895 & 0.915 & $\begin{array}{c}0.076(0.069 \\
0.082) /<0.001\end{array}$ & 0.035 & 666.08 & 1.06 \\
\hline WB-4r & $\begin{array}{c}615.84 \\
(129) /<0.001\end{array}$ & 4.77 & 0.907 & 0.890 & $\begin{array}{c}0.078(0.071 \\
0.084) /<0.001\end{array}$ & 0.035 & 699.81 & 1.11 \\
\hline
\end{tabular}

Note: The revised model ( 18 items) is highlighted in bold; $\chi 2=$ chi-square; $\mathrm{df}=$ degree of freedom; TLI $=$ TuckerLewis fit index; CFI = comparative fit index; RMSEA = root mean square error of approximation; $90 \% \mathrm{CI}=90 \%$ confidence interval; Clfit = close fit; SRMR = standardized root mean square residual; AIC = Akaike information 
criterion; ECVI = expected cross-validation index; WB-5 = five-factor model of Malaysian index of elderly wellbeing; WB-5r = five-factor model of Malaysian index of elderly well-being (revised); WB-4r = four-factor model of Malaysian index of elderly well-being (revised).

The four-factor model with social and environmental well-being was named as WB-4r. The fit indices for WB-4r is presented in Table 2. The model showed an acceptable fit except for CFI and $\chi 2$.

In order to decide the final revised model, WB-5r and WB-4r model were compared in terms of model fit indices and model improvement. Model fit indices showed that WB-5r provided a better model fit. On assessment of model improvement based on the initial model, reduction of values of AIC and ECVI showed WB$5 \mathrm{r}$ provided better model improvement compared with WB-4r. Therefore, model WB-5r was the five-factor model accepted as the final model for this study (Figure 1). The item factor loadings for WB-5r are presented in Table 3.

Table 3: Factor loadings and composite reliability for model WB-5r

\begin{tabular}{lclcc}
\hline \multicolumn{1}{c}{ Factor } & Item & \multicolumn{1}{c}{ Description } & FL & CR \\
\hline \multirow{5}{*}{ Social } & Q7 & I have close relationship with family members & 0.67 & \\
& Q19 & $\begin{array}{l}\text { I am in contact with my immediate family (parents, } \\
\text { children, siblings) }\end{array}$ & 0.74 & \\
& Q20 & I am in contact with friends & 0.76 & 0.91 \\
& Q29 & I have someone whom I love & 0.64 & \\
& Q30 & My opinion/ advice is always considered by my family & 0.76 & \\
& Q39 & I have someone as a confidante & 0.70 & \\
\hline \multirow{5}{*}{ Economic } & Q9 & I have savings and assets for old age & 0.75 & \\
& Q10 & I have money for daily expenses & 0.74 & 0.86 \\
& Q24 & I always have money for emergencies & 0.71 & \\
\hline \multirow{2}{*}{ Health } & Q11 & I can manage my stress & 0.74 & \multirow{2}{*}{0.77} \\
& Q12 & I maintain a healthy weight & 0.67 & \\
\hline \multirow{5}{*}{ Environment } & Q27 & I feel secure in my house & 0.68 & \\
& Q28 & I can move easily in my house & 0.77 & \multirow{2}{*}{0.83} \\
& Q38 & I live in a close-knit neighbourhood & 0.66 & \\
\hline \multirow{5}{*}{ Spiritual } & Q3 & I am at peace with myself & 0.70 & \\
& Q4 & Life is beautiful & 0.81 & \multirow{2}{*}{0.91} \\
& Q26 & I have a meaningful life & 0.78 & \\
& Q36 & My life is enjoyable & 0.78 & \\
\hline
\end{tabular}

Note: $\mathrm{FL}=$ factor loading; $\mathrm{CR}=$ composite reliability 


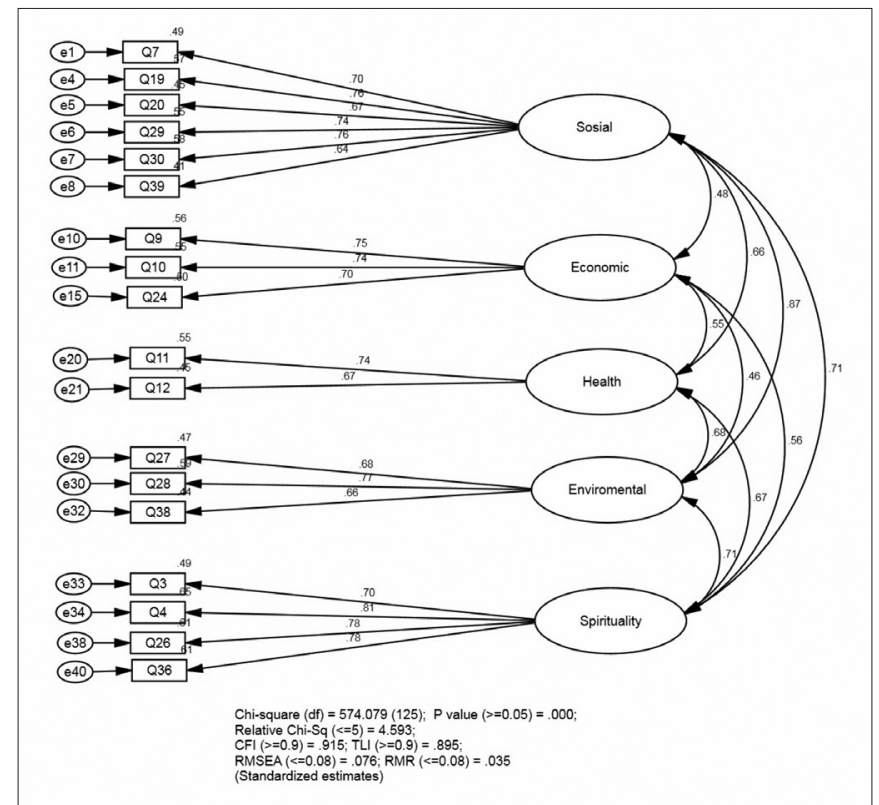

Figure 1: The five-factor model of the Malaysian Index of Elderly Well-being (revised)

The convergent validity of WB-5r was represented by high item factor loadings in their factor, acceptable values of AVE (Table 4) and high construct reliability (Table 3). The discriminant validity of the model was indicated by comparing the factor's AVE with its squared factor correlations, and it was at a satisfactory level. The squared factor correlation of social and environment with a value of 0.76 exceeded its factor's AVEs (social $=0.51$ and environment $=$ 0.51) (Table 4).

Table 4: AVE, factor correlations and squared factor correlations for model WB-5r

\begin{tabular}{lcccccc}
\hline Factor & AVE & $(1)$ & $(2)$ & $(3)$ & $(4)$ & $(5)$ \\
\hline Social (1) & $0.51^{\mathrm{a}}$ & - & 0.48 & 0.66 & 0.87 & 0.71 \\
Financial (2) & 0.54 & $\mathbf{0 . 2 3}$ & - & 0.55 & 0.46 & 0.56 \\
Health (3) & 0.50 & $\mathbf{0 . 4 3}$ & $\mathbf{0 . 3 1}$ & - & 0.68 & 0.68 \\
Environment (4) & $0.50^{\mathrm{a}}$ & $\mathbf{0 . 7 6}$ & $\mathbf{0 . 2 2}$ & $\mathbf{0 . 4 7}$ & - & 0.71 \\
Spiritual (5) & 0.59 & $\mathbf{0 . 5 1}$ & $\mathbf{0 . 3 1}$ & $\mathbf{0 . 4 6}$ & $\mathbf{0 . 5 0}$ & - \\
\hline
\end{tabular}

Note: Squared factor correlations are highlighted in bold and factor correlations are highlighted in italic; AVE = average variance extracted

a Squared factor correlation exceeds AVE of its factor

\section{Discussion}

To recapitulate, MIEW consisted of five factors. The factors were proposed and revised by experts during the item development and content validity. The proposed five-factor model of MIEW fit well after extensive item removal. Of the total 40 items, 22 items $(55 \%)$ were removed from initial model $(.2(\mathrm{df})=$ 574.08 (125), $\mathrm{P}<0.001$; relative. $2=4.59$; $\mathrm{TLI}=0.895 ; \mathrm{CFI}=0.915 ; \mathrm{RMSEA}=0.076$; SRMR $=0.035$ ).

The objective of this study was to determine the construct validity and 
reliability of the new Malaysian Index of Elderly Well-being. The MIEW was shown to have an acceptable construct validity and reliability. Construct validity are often discussed in relation to convergent and discriminant validity (Din et al., 2020). The convergent validity of MIEW was demonstrated by high item factor loadings in their factors. However, there was an uncertainty of MIEW discriminant validity through the assessment of AVE and squared factor correlations. The factors were shown to have strong discriminant validity, except for social and environmental well-being. Squared factor correlations between social and environmental well-being (0.76) exceed its factor AVE (Social $=0.51 \&$ Environment $=0.50$ ), resulting in poor discriminant validity of the factors. One may speculate that the high correlation between the factors might indicate a similarity of the factor items, resulting to respondents being unable to differentiate them. A tentative argument is advanced that the convergence of the two factors may be attributed to the overlap between physical and social environments as the items represented the social derivatives of belongingness, safety and security (Fullilove, 2001). The reliability of MIEW was demonstrated by the high construct reliability.

The current study, which involved a relatively large sample size and used a standardised methodology, is one of the first attempts to develop and validate a tool to assess elderly well-being among the elderly in Malaysian. The findings showed that the tool showed acceptable validity and reliability. However, the tool should be used with caution until further evidence on the uncertainty is presented. There are potential limitations of the current study that should be considered. Firstly, the lack of a gold standard measure of elderly wellbeing against which to test the sensitivity and specificity of MIEW. The evident of validity according to internal structure and the relations with other variables (or factor scores in other inventories) of MIEW could not be compared with other existing inventories because of the differences in the theoretical background and the statistical approach used in the development of the inventories (Din et al., 2018). These differences were clearly described in a systematic review by Nolan et al. (2012), in which the theoretical number of factors, the factor definitions, and the statistical approach used in the evaluation of internal structure differed significantly. Secondly, this study did not examine the test-retest reliability to test the stability of MIEW items. Fourth, this study only examined the content, face and construct validity of MIEW. Further research is recommended to examine other types of validity for a tool, including predictive validity, criterion validity and concurrent validity. Lastly, the current study sample proportion of ethnicity did not reflect the Malaysian ethnicity proportion. A cross validation study with sample ethnicity proportioned to the Malaysian population is recommended.

\section{Conclusion}

In sum, the findings of this study provide preliminary evidence of the validity and reliability of MIEW. It is a complex index incorporating the different dimensions of well-being as indicated in the national policy. As it is built up from the various factors, it can easily be broken down by factors. Nevertheless, it could be strengthened in a number of areas through better data, inclusion of objective factors, and the clarification of the underlying theoretical specification for specific domains. MIEW may be used with specific instructions as a screening tool for the measurement of elderly well-being in the community. Scientific evidence generated from this index is useful in addressing international and national requirements to report the well-being of the population. 


\section{Acknowledgements}

Authors wish to thank the University for research facilities and the reviewers and editors for the comments on this manuscript.

\section{References}

Awang, Z. (2012). Structural equation modeling using AMOS graphic: Penerbit Universiti Teknologi MARA.

Bentler, P. M. (1990). Comparative fit indexes in structural models. Psychological bulletin, 107(2), 238.

Brown, T. A. (2014). Confirmatory factor analysis for applied research: Guilford Publications.

Byrne, B. M. (2010). Structural equation modeling with AMOS: Basic concepts, applications, and programming. Abingdon: Routledge Academic.

Choudhary, M. A., Levine, P., McAdam, P., \& Welz, P. (2011). The happiness puzzle: analytical aspects of the Easterlin paradox. Oxford Economic Papers, 64(1), 27-42.

Converse, P. E., \& Rodgers, W. L. (1976). The quality of American life: Perceptions, evaluations, and satisfactions: New York: Russell Sage Foundation.

Diener, E., \& Suh, E. (1997). Measuring quality of life: Economic, social, and subjective indicators. Social indicators research, 40(1-2), 189-216.

Diener, E. D., Emmons, R. A., Larsen, R. J., \& Griffin, S. (1985). The satisfaction with life scale. Journal of Personality Assessment, 49(1), 71-75. https://doi. org/10.1207/s15327752jpa4901_13

Din, H. M., Arifin, W. N., Abdullah, S., Yusoff, M. S. B., \& Aziz, A. A. (2018). The Internal Structure of New Attitudes towards Statistics Inventory among Postgraduate Students in Medical and Health Sciences. Education in Medicine Journal, 10(4). https://doi. org/10.21315/eimj2018.10.4.6

Fornell, C., \& Larcker, D. F. (1981). Evaluating Structural Equation Models with Unobservable Variables and Measurement Error. Journal of Marketing Research, 18(1), 39-50. https://doi.org/10.2307/3151312

Fullilove, M. T. (2001). Links between the social and physical environments. Pediatric Clinics of North America, 48(5), 1253-1266.

Hair, J., Black, W., \& Balin, B. (2009). BJ, \& Anderson, RE (2010). Multivariate data analysis, 7 .

Hair, J. F., Black, W. C., Babin, B. J., Anderson, R. E., \& Tatham, R. L. (2006). Multivariate data analysis (Vol. 6): Upper Saddle River, NJ: Pearson Prentice Hall.

Helliwell, J. F., \& Putnam, R. D. (2004). The social context of well-being. Philosophical Transactions of the Royal Society B: Biological Sciences, 359(1449), 1435.

Hoque, A., Awang, Z., Jusoff, K., Salleh, F., \& Muda, H. (2017). Social Business Efficiency: Instrument Development and Validation Procedure using Structural Equation Modelling. International Business Management, 11(1), 222-231.

Ju, H., Shin, J. W., Kim, C.-w., Hyun, M.-h., \& Park, J.-W. (2013). Mediational effect of meaning in life on the relationship between optimism and well-being in community elderly. Archives of Gerontology and Geriatrics, 56(2), 309-313. doi: https://doi.org/10.1016/j. archger.2012.08.008

Kahn, R. L., \& Juster, F. T. (2002). WellBeing: concepts and measures. Journal of Social Issues, 58(4), 627-644. 
Joseph, S., Linley, P. A., Harwood, J., Lewis, C. A., \& McCollam, P. (2004). Rapid assessment of well being: The short depression happiness scale (SDHS). Psychology and Psychotherapy: Theory, Research and Practice, 77(4), 463-478. https://doi. org/1476083042555406

Luchesi, B. M., de Oliveira, N.A., de Morais, D., de Paula Pessoa, R. M., Pavarini, S. C. I., \& Chagas, M. H. N. (2018). Factors associated with happiness in the elderly persons living in the community. Archives of Gerontology and Geriatrics, 74, 83-87. https://doi. org/10.1016/j.archger.2017.10.006

Mat Din, H., Raja Adnan, R., \& Minhat, H. (2020). Psychometric properties of mos social support survey among malaysian community-dwelling older adults. Asian Journal Of Research In Education And Social Sciences, 2(1), 62-73.

Meléndez, J. C., Tomás, J. M., Oliver, A., \& Navarro, E. (2009). Psychological and physical dimensions explaining life satisfaction among the elderly: A structural model examination. Archives of Gerontology and Geriatrics, 48(3), 291-295. doi: https://doi.org/10.1016/j. archger.2008.02.008

Naess, S. (1999). Subjective approach oo quality of life. Feminist Economics, 5(2), 115-118.

Nolan, M. M., Beran, T., \& Hecker, K. G. (2012). Surveys assessing students'attitudes toward statistics: a systematic review of validity and reliability. Statistics Education Research Journal, 11(2).

Ryan, R., \& Deci, E. (2001). To be happy or to be self-fulfileld: A review of research on hedonic and eudaimonic well-being. Annual Review of Psychology, 52(16), 141-166.
Ryff, C. D., \& Keyes, C. L. M. (1995). The structure of psychological well-being revisited. Journal of Personality and Social Psychology, 69(4), 719. https:// doi.org/10.1037/0022-3514.69.4.719

Sen, A. K. (2001). Development as freedom: Oxford University Press.

Sim, O. F., \& Hamid, T. A. (2010). Social protection in Malaysia-current state and challenges towards practical and sustainable social protection in East Asia: A compassionate community. Social Protection in East Asia-Current State And Challenges, 182.

Tabachnick, B. G., \& Fidell, L. S. (2007). Using multivariate statistics. Boston, MA: Allyn \& Bacon/Pearson Education.

Tennant, R., Hiller, L., Fishwick, R., Platt, S., Joseph, S., Weich, S., Parkinson, J., Secker, J., \& Stewart-Brown, S. (2007). The Warwick-Edinburgh mental wellbeing scale (WEMWBS): Development and UK validation. Health and Quality of life Outcomes, 5(1), 63. https://doi. org/10.1186/1477-7525-5-63

United Nations Economic and Social Commission for Asia and the Pacific Social Development Division. (2017). Ageing in Asia and the Pacific: Overview. Retrieved from http://mipaa.unescapsdd.org/files/ documents/SDD\%20Ageing\%20 Fact\%20Sheet\%20Overview.pdf

Watson, D., Clark, L. A., \& Tellegen, A. (1988). Development and validation of brief measures of positive and negative affect: the PANAS scales. Journal of Personality and Social Psychology, 54(6), 1063. 
